\title{
Political Price Cycles in Regulated Industries: Theory and Evidence
}

\author{
Claudio Paiva and Rodrigo Moita
}





\title{
IMF Working Paper
}

Western Hemisphere Department

Political Price Cycles in Regulated Industries: Theory and Evidence

Prepared by Claudio Paiva and Rodrigo Moita

Authorized for distribution by Trevor S. Alleyne

November 2006

\begin{abstract}
This Working Paper should not be reported as representing the views of the IMF. The views expressed in this Working Paper are those of the author(s) and do not necessarily represent those of the IMF or IMF policy. Working Papers describe research in progress by the author(s) and are published to elicit comments and to further debate.

This paper develops a model of political regulation in which politicians set the regulated price in order to maximize electoral support by signaling to voters a pro-consumer behavior. Political incentives and welfare constraints interact in the model, yielding an equilibrium in which the real price in a regulated industry may fall in periods immediately preceding an election. The paper also provides empirical support for the theoretical model. Using quarterly data from 32 industrial and developing countries over 1978-2004, we find strong statistical and econometric evidence pointing toward the existence of electoral price cycles in gasoline markets.
\end{abstract}

JEL Classification Numbers:K20, L51, E32

Keywords: Political cycle, regulated prices, gasoline prices

Authors’ E-Mail Addresses: cpaiva@,imf.org; rodmoita@gmail.com 


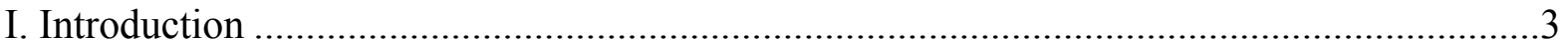

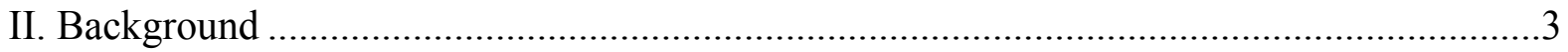

III. A Model of a Political Price Cycles in a Regulated Industry ........................................5

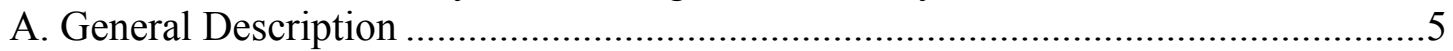

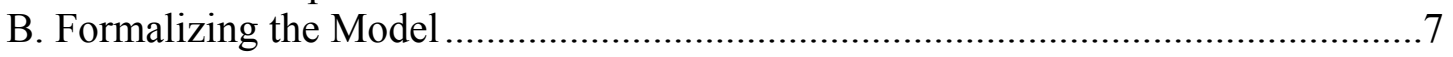

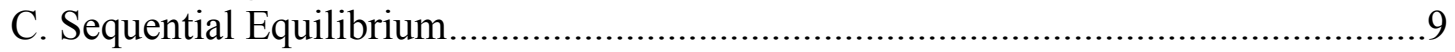

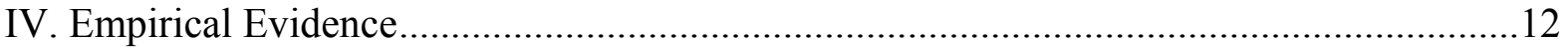

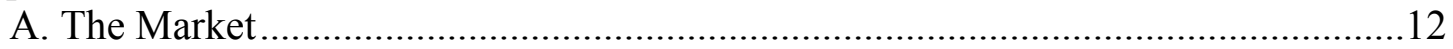

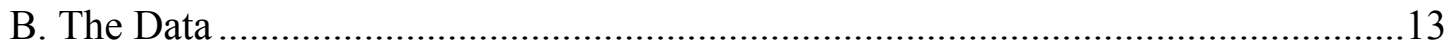

C. Econometric Modeling .................................................................................. 14

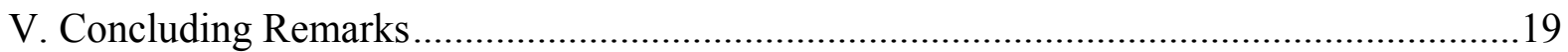

Tables

1. Real Gasoline Prices, Oil Costs, and Elections: Basic Model ..........................................16

2. Real Gasoline Prices, Oil Costs, and Elections: Modified Basic Model ............................17

3. Real Gasoline Prices, Oil Costs, and Elections: Alternative Model ..................................18

Figures

1. Chronological Order of Events ...............................................................................

Appendix

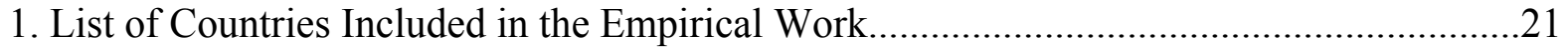

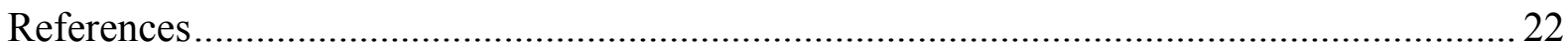




\section{INTRODUCTION}

The relationship between politics and economic policy has a long tradition in economic analysis. One important approach links macroeconomic policy decisions to the electoral cycle and has become known in the literature as the political business cycle theory. Pioneered by Nordhaus (1975), this theory claims that macroeconomic aggregates - such as the money supply and the government budget - are likely to follow a cycle driven by electoral interests, as incumbent politicians distort economic policy to deceive myopic voters and obtain shortterm political gains. Rogoff and Sibert (1988) and Rogoff (1990) refine this approach by characterizing the political business cycle as the equilibrium of a signaling game that arises due to a temporary information asymmetry between government and fully rational voters.

Another important line of research that relates economic policy decisions to the electoral cycle focuses on industry-level issues and treats the regulatory process as the arbitration of conflicting social, economic, and political interests rather than a pure welfare-maximizing effort. This approach originated from the early work of Stigler (1971) and was further developed in Peltzman (1976) with the introduction of a formal model in which the regulated price is chosen so as to maximize political support for the incumbent government-regulator.

This paper follows Paiva (1996) in combining elements of both approaches described above: the idea that policy decisions may change with the proximity of elections is borrowed from the political business cycle theory and added to enhance the traditional, static models of political regulation. More specifically, we combine the main ideas of Peltzman (1976) and Rogoff and Sibert (1988) to model the regulator's problem as a signaling game where politicians set the regulated price in order to maximize electoral support by signaling to voters a pro-consumer behavior. Political incentives and welfare constraints interact in the model, yielding an equilibrium in which the real price in a regulated industry may fall in periods immediately preceding an election. Besides presenting a new model of political price cycles in regulated industries, this paper also provides empirical support for this theory. Using quarterly data from 32 industrial and developing countries over 1978-2004, we find strong statistical and econometric evidence pointing toward the existence of electoral price cycles in gasoline markets.

The next section broadly describes the evolution of the ideas embedded in the theories of political business cycles and political regulation that form the basis for our theory of electoral cycles in regulated industries. In the third section we introduce our model of dynamic political regulation and derive the results that characterize the political price cycle in regulated industries. Section four presents the empirical evidence supporting the results of our model.

\section{BACKGROUND}

In his groundbreaking work on political business cycle, Nordhaus (1975) predicted that governments would inflate the economy in election years in order to exploit a Philips curve trade off that is beneficial in the short but not in the long run. His model assumed that 
consumers have adaptive expectations about inflation and are myopic in the sense that they partially forget, or heavily discount, the past. Regardless of their party affiliation, politiciansturned-policymakers are assumed to be opportunistic and only care about being re-elected. The model implies that (1) in an election year the government uses expansionary policies to decrease unemployment; (2) concerns about inflation only arise after the election; and (3) every government follows the same policy. A common criticism of this type of model is that rational voters would understand the motivation for and the consequences of distorting the optimal policy in election years, therefore making politicians less likely to adopt such strategy.

However, Tufte (1978), among others, provided further empirical evidence of the occurrence of political business cycles and new models were developed to explain the phenomenon. Abandoning the old assumptions of adaptive expectations and myopic voters, Rogoff and Sibert (1988) and Rogoff (1990) rationalize the political business cycle as the equilibrium of a signaling game originated from a temporary information asymmetry between government and voters. Governments can be differentiated by their level of competency, with more competent governments providing the same amount of services using less resources. Government competency is modeled as a serially correlated stochastic variable that receives a new shock every period. Information asymmetry arises from the fact that the government learns its competency shock before voters do. In election years, the incumbent party has an incentive to act as if it had received a high-competency shock, otherwise voters may prefer an opposition party that can do better in the next period. In equilibrium, most governments will lower nondistortionary taxes (collected before the elections) and increase distortionary taxes (collected after the elections) in election years in order to signal their types. The least efficient type of government is the only one who will not distort the taxation.

The pioneering work of Stigler (1971) claims that industry regulation should be viewed as a way to arbitrate among competing interests rather than a way to maximize welfare. Regulators would make their decisions about price, market entry, and other relevant variables under pressure from different interest groups. The regulatory outcome is therefore determined by transactions between self-interested suppliers and demanders. The suppliers are the regulators (with no distinction from the government) that sell wealth transfers in the form of regulated prices and industry entry. The demanders are the interest groups, namely, consumers and firms, who bid to be favored in the wealth transfer process. The equilibrium of Stigler's model is one in which, in the words of Peltzman (1993), "cohesive minorities tax diffuse majorities," and the process ends with the capture of the regulatory agency by the firms. This conclusion refers to the fact that consumers have weak incentives to acquire information or actively defend their interests in a particular industry since each individual regulatory decision has only a limited impact on consumers' utility. In contrast, producers have a strong enough interest on the regulatory outcome in their industry so as to form pressure groups to influence the political process.

Building on Stigler's work, Peltzman (1976) and Becker (1983) develop models that introduce a broader range of political influence of interest groups. In particular, Peltzman's model formalizes the idea that a regulatory agency chooses a price that maximizes political support 
for the incumbent government-regulator. Political support depends on the profits of the regulated firm(s) and on consumers' surpluses. Given that profits (consumers' surpluses) increase (decrease) at a decreasing (increasing) rate, the regulated price that maximizes political support will lie between the monopoly and the competitive price. This conclusion differs from the previous work of Stigler in which the optimal regulated price was close to the monopoly price reflecting a very high degree of industry protection.

Paiva (1996) modifies Peltzman's model by adding a time dimension to the regulator's maximization problem. The main idea is that the regulator's behavior changes with the proximity of elections, securing higher profits and campaign donations from firms in nonelection periods and becoming more concerned with consumers' interests in periods immediately preceding elections. In line with Stigler's view of diffused consumer interests, Paiva's model assumes that consumers do not keep track of past prices and that their voting decisions are more affected by current prices and utility. In contrast, firms have a large stake in the regulatory process and have (or acquire) information about past prices. The equilibrium of the model is one in which the solution to the intertemporal maximization problem of the regulator yields lower prices in periods preceding the election, characterizing an electoral cycle in regulated prices. One important weakness of this model is the reliance on myopic consumer-voters or their heavy discounting of past regulatory decisions. We address this problem by redefining the regulator problem as a competency or preference-signaling game, as shown in the following section.

\section{A Model of a Political Price Cycles in a Regulated Industry}

\section{A. General Description}

We combine the main ideas of Rogoff and Sibert (1988) and Peltzman (1976) and model the government-regulator's problem as a signaling game where the cycle is generated by politicians trying to signal pro-consumer behavior to voters when setting the regulated price. We deal with the discrete version of the problem where there are only two possible types of government-regulator: pro-industry and pro-consumer. Contrary to the continuous case developed in Rogoff and Sibert, here we are able to derive a closed-form solution to the model in which regulators' strategies may lead to a political cycle in the regulated price.

The government-regulator sets prices in a regulated industry seeking to maximize an intertemporal objective function which includes social welfare but also the government's chance of being reelected. The social welfare function in the regulated market is a weighted average of consumers' utility and industry profits in which the weights follow a stochastic process. Elections take place every other period. In a nonelectoral year the incumbent government-regulator chooses the price that maximizes welfare in the regulated market. In an election year, however, the incumbent may lower the regulated price to increase its chance of being reelected. It is assumed that firms in the regulated industry cannot affect the result of the 
election. ${ }^{1}$ Consumers decide their votes influenced in part by the incumbent's pricing decision and in part by an exogenous shock to their utility function. This shock to consumers' utility could be related to the performance of the government in other areas, for instance.

We model the government-regulator's social welfare function as stochastic process in which the relative weight of consumers' utility and industry profits is determined by a shock occurring at the beginning of every election period. In principle, a shock that determines a higher (lower) weight on firms' profits characterizes a pro-industry (pro-consumer) type of regulator and results in the choice of a higher (lower) regulated price. For instance, a shock that makes the incumbent more pro-industry could be thought of as resulting from (1) a recently formed political coalition that attributes higher importance to securing future investment in the sector; (2) external constraints that limit the country's capacity to import the regulated product, thus requiring an increase in domestic production and the profits to sustain it; or (3) a negative fiscal shock elsewhere that would either increase the need to extract additional income taxes from firms in the regulated industry or at least reduce the ability of the regulator to provide compensatory transfers to regulated firms in a low-price environment.

The shock that determines whether the incumbent government-regulator is pro-consumer or pro-industry is not observed by the voters until after the election. ${ }^{2}$ This temporary information asymmetry makes it possible for a pro-industry regulator to try and mimic the behavior of a pro-consumer type by setting a lower price and increasing its chances of winning the election. However, since deviations from the welfare-maximizing price generate a decrease in welfare at increasing rates, pro-consumer regulators can achieve a lower price than pro-industry regulators for any given level of welfare. Therefore, in equilibrium, the pro-consumer regulator will set a price unachievable by the pro-industry type in order to unequivocally signal its type to consumer-voters. Unable to match this lower price, pro-industry regulators have no reason to distort the regulated price in equilibrium.

The order of events is what drives the cycle. At the beginning of the period $(t)$ the incumbent receives its preference shock and sets the regulated price. Afterward, the election happens, the winner is announced, and the period ends. At the beginning of the following period $(t+1)$, the winner of the election takes office until the end of the next period $(t+2)$. Note that a new preference shock will define a new orientation for the incumbent at the beginning of period $t+2$, and another election will then take place. The incumbent type is revealed to the public at

\footnotetext{
${ }^{1}$ This assumption rules out the possibility of raising the regulated price in exchange for campaign donations from the industry. However, the regulator does not set the price equal to marginal cost (the most pro-consumer price-see Peltzman, 1976) since the industry has a positive weight in the government-regulator's social welfare function.

${ }^{2}$ The fact that consumers cannot observe the pro-consumer shock of the government can be justified by the fact that the regulated price is one among several prices that matter to consumers, and gathering information about the situation of the shock on profitability is too costly compared to the value of one vote.
} 
period $t+1$, since the regulator will set the post-election price that maximize its social welfare function, with no electoral concerns.

\section{B. Formalizing the Model}

The firm's profit function is given by

$$
\pi=p_{t} q_{t}-C\left(q_{t}\right)
$$

where $\pi$ is the profit of the firm, $p_{t}$ is the price of the regulated good, $q_{t}$ is the quantity produced-demanded of the good and $C(q)$ is the cost function, that we assume to be continuous differentiable with $C_{q}>0$ and $C_{q q}>0$.

Consumer-voters' utility function is given by,

$$
U\left(q_{t}\right)=\phi\left(q_{t}\right)+\eta_{t}^{I}
$$

with $\phi^{\prime}>0$ and $\phi^{\prime \prime}<0$, and $\eta_{t}$ is a random variable related to the government's performance in areas other than the regulated market that also reflect on its popularity. It follows

$$
\eta_{t}^{I}-\eta_{t}^{o}=s_{t}+s_{t-1}
$$

where $s_{t}$ is iid with a unimodal distribution, twice continuously differentiable with mean zero. The superscripts $I$ and $O$ refer to incumbent and opposition parties. Given prices, consumers maximize their utility subject to the budget constraint, what gives the demand function $q=q(p)$ for the good.

The type of the politician is defined by $\alpha$, where $\alpha \in\{\underline{\alpha}, \bar{\alpha}\}$, with $\underline{\alpha}$ being the pro-consumer type and $\bar{\alpha}$ being the pro-industry type, $\underline{\alpha}<\bar{\alpha}$ and $\operatorname{Prob}(\alpha=\bar{\alpha})=\mu$. The value of $\alpha$ refers only to the incumbent, and the fact that the shock in time $t$ will define the type in periods $t$ and $t+1$ is what drives the signaling problem of the incumbent; otherwise the type of politicianregulator today would be disconnected from her type in the next period, and would not have any influence in voters' decision.

The incumbent has the following social welfare function,

$$
W(\alpha)=\mu . \pi(p(\alpha))+(1-\mu) V(p(\alpha))
$$

where $V(p(\alpha))$ is the indirect utility of the consumer. However, the objective function of the government is a finite horizon maximization problem, where he decides the regulated price in the two periods that he will be in office. 


$$
\Phi_{t}^{I}=\max _{p(\alpha)} E_{t}\left[\sigma \cdot \beta \cdot R_{t+1}^{I}+\sum_{i=t}^{t+1} \beta^{i-t} W\left(\alpha_{i}\right)\right]
$$

where $\mathrm{R}$ is the probability of the incumbent being reelected and will be formalized below; $\sigma$ is the weight the party places on being elected relative to social welfare; and $\beta<1$ is a discount factor. The opposition party has a similar objective function.

The game has the following chronological order (Figure 1): At the beginning of the period the government observes its own shock $\alpha_{t}$. Next, the regulatory process takes place and the regulated price $p_{t}$ is set and observed by all agents. After the price is set, government and consumers observe the popularity shock of the incumbent, $s_{t}$, and the election happens. In the following period, $t+1$, the party that wins the elections takes office until $t+2$, when elections will be held again.

Figure 1. Chronological Order of Events

\begin{tabular}{|c|c|c|c|c|}
\hline $\begin{array}{l}\text { The government } \\
\text { observes } \alpha_{t} \text {, and } \\
\text { the regulatory } \\
\text { process takes } \\
\text { place, where the } \\
\text { price } p_{t} \text { is set. }\end{array}$ & $\begin{array}{l}\text { Both government } \\
\text { and consumers } \\
\text { observe the } \\
\text { popularity shock } s_{t} \text {, } \\
\text { and elections } \\
\text { happen. }\end{array}$ & $\begin{array}{l}\text { The winner of } \\
\text { the elections } \\
\text { takes office } \\
\text { until the end of } \\
\text { next period. } \\
\text { Price } p_{\mathrm{t}+1} \text { is set. }\end{array}$ & $\begin{array}{l}\text { The winner of the } \\
\text { elections at time } t \\
\text { is still in office, but } \\
\text { a new shock } \alpha_{t+2} \\
\text { occurs and price } \\
p_{t+2} \text { is set. }\end{array}$ & $\begin{array}{l}\text { Both government } \\
\text { and consumers } \\
\text { observe a new } \\
\text { popularity shock } s_{t+2} \\
\text { and elections } \\
\text { happen. }\end{array}$ \\
\hline$t$ & & +1 & $t+2$ & \\
\hline
\end{tabular}

It is important to notice that the government has an advantage over the public regarding access to information, since it observes the shock $\alpha$ before the public does. Voters only infer the shock and resulting government type at the beginning of the next period, $t+1$, when the incumbent announces the new price. That is what allows the government to try and mimic a different type to the public: incumbents with higher $\alpha$ have an incentive to act as if they have a lower one.

The incumbent party wins the election in period $t$ if

$$
E_{t}\left[V_{t+1}^{I}+V_{t+2}^{I}-\left(V_{t+1}^{O}+V_{t+2}^{O}\right)\right] \geq 0
$$

The shock received in period $t$ provides no information about the shock (and the price) in period $t+2$ (the time of the next election), since a new shock happens in $t+2$. Therefore

$$
E_{t}\left[V_{t+2}^{I}\right]=E_{t}\left[V_{t+2}^{O}\right]
$$


So we have,

$$
\begin{gathered}
E_{t}\left[V_{t+1}^{I}-V_{t+1}^{O}\right]=E_{t}\left[\phi\left(q\left(p_{t+1}^{I}\right)\right)+\eta_{t+1}^{I}-\phi\left(q\left(p_{t+1}^{O}\right)\right)-\eta_{t+1}^{O}\right]=E_{t}\left[\phi\left(q\left(p_{t+1}^{I}\right)\right)-\phi\left(q\left(p_{t+1}^{O}\right)\right)+s_{t+1}+s_{t}\right] \\
E_{t}\left[V_{t+1}^{I}-V_{t+1}^{O}\right]=E_{t}\left[\phi\left(q\left(p_{t+1}^{I}\right)\right)\right]-\phi(q(\hat{p}))+s_{t}
\end{gathered}
$$

where $\hat{p}$ is the mean value of $p$, and the expectation is taken conditional on the information available to the public in time $t$.

The incumbent party does not observe $s_{t}$ when it sets the price $p_{t}$, hence the probability of winning is given by,

$$
\operatorname{Pr} o b\left[E_{t}\left[\phi\left(q\left(p_{t+1}^{I}\left(\alpha_{t}\right)\right)\right)\right]-\phi(q(\hat{p}))+s \geq 0\right]=R_{t}^{I}\left[\alpha_{t}\right]
$$

and it follows the probability distribution of $s$, and $R^{O}=1-R^{I}$. A high value of the popularity shock $s$ increases the chances of winning the election, since it increases the voters' utility. At the time the incumbent sets the price he cannot observe the popularity shock, so there is no relation between the price and $s_{t}$. That is why the probability of winning the election follows the distribution of the popularity shock.

\section{Sequential Equilibrium}

To find the equilibrium of the model we rely on the fact that each election cycle is independent of past election cycles. First, this is due to the fact that the shock in time $t$ will not have any influence in time $t+2$, and also because the information asymmetries are only temporary. Second, there is no history dependence in this model, in the sense that reputational aspects do not enter the problem.

We start assuming that in equilibrium voters recognize the incentive to lower prices in election years and are able to make the mapping between $\alpha$ and the regulated price. So, voters' beliefs about $\alpha$ as a function of $p$ are given by,

$$
\widetilde{p}_{t}=\tilde{p}\left(\alpha_{t}\right)
$$

The assumption that beliefs about price depend only on the current shock implies that incumbents decisions about price affect only the current period. It turns out that the otherwise dynamic problem of the incumbent becomes a static maximization problem, where the incumbent sets the regulated price that maximizes that year's objective function. Hence, the objective function of the incumbent in an election year reduces to,

$$
\Phi_{t}^{I}=\max _{p(\alpha)}\left[\sigma R_{t}^{I}+W\left(\alpha_{t}\right)\right]
$$


And in a nonelectoral year $t+1$ it becomes,

$$
\Phi_{t+1}^{I}=\max _{p(\alpha)} W\left(\alpha_{t}\right)
$$

Since the objective function in a nonelectoral year is the welfare function itself, in equilibrium the incumbent sets the regulated price to the level that maximizes the welfare function in nonelectoral years. Now we turn to the pricing problem in electoral years. We dropped the subscript $t$ for simplicity of notation keeping in mind that all the analysis that follows refer to electoral years.

Before characterizing the equilibrium we need some new definitions. Define $W(\alpha, p)$ as the value of the social welfare function when the politician chooses price $p$ and $p^{*}(\alpha)=\arg \max W(\alpha, p)$. Also, define the difference in welfare when type $\alpha$ chooses $p$ or $p^{\prime}$ as $\lambda\left(p-p^{\prime}\right)=W(\alpha, p)-W\left(\alpha, p^{\prime}\right)$. Therefore, when type $\alpha$ chooses $p(\alpha)$, $\lambda\left(p^{*}(\alpha)-p(\alpha)\right)=W\left(\alpha, p^{*}(\alpha)\right)-W(\alpha, p(\alpha))$ gives a measure of the distortion that type $\alpha$ creates from deviating from the welfare maximizing price $p^{*}(\alpha)$.

Now we characterize the separating equilibrium of this signaling game. In equilibrium the incumbent politician adopts the following strategies: if pro-industry type he sets $p(\bar{\alpha})=p^{*}(\bar{\alpha})$ and $\lambda\left(p^{*}(\bar{\alpha})-p(\bar{\alpha})\right)=0$; if pro-consumer type sets $p(\underline{\alpha})<p^{*}(\underline{\alpha})$ and $\lambda\left(p^{*}(\underline{\alpha})-p(\underline{\alpha})\right)>0$. Any voters' beliefs that assign probability one of being a high type when observing $p(\bar{\alpha})$, and probability one of being a low type when observing $p(\underline{\alpha})$ is consistent with this equilibrium. This is the well known result first derived by Spence (1973) that the least favored type (with respect to voters) does not try to signal his type since in equilibrium he will be recognized anyway.

Proposition: In a separating equilibrium $p(\bar{\alpha})=p^{*}(\bar{\alpha})$ and $\lambda\left(p^{*}(\bar{\alpha})-p(\bar{\alpha})\right)=0$.

Proof: Suppose not. Instead, $p(\bar{\alpha})<p^{*}(\bar{\alpha})$ and $\lambda\left(p^{*}(\bar{\alpha})-p(\bar{\alpha})\right)=\kappa>0$. There would be a decreasing in welfare of $\kappa$. But since in equilibrium the high type $\bar{\alpha}$ would be recognized as such, there would be no increase in the probability of being reelected. Therefore, the high type is better off by setting $p(\bar{\alpha})=p^{*}(\bar{\alpha})$ and $\lambda\left(p^{*}(\bar{\alpha})-p(\bar{\alpha})\right)=0$.

Theorem: A separating sequential equilibrium of this game has

$$
p(\underline{\alpha})=p^{*}(\bar{\alpha})-\lambda^{-1}[\sigma[R[\underline{\alpha}]-R[\bar{\alpha}]]]
$$

Proof: Sequential rationality of the game requires that no player finds it better off to deviate from the equilibrium path. This implies the following conditions:

$$
\Phi(\underline{\alpha}, \underline{\alpha}) \geq \Phi(\underline{\alpha}, \bar{\alpha})
$$




$$
\Phi(\bar{\alpha}, \bar{\alpha}) \geq \Phi(\bar{\alpha}, \underline{\alpha})
$$

where the first term within the parentheses is the true type of the incumbent, and the second term is the one he is trying to mimic. The first inequality, $\Phi(\underline{\alpha}, \underline{\alpha}) \geq \Phi(\underline{\alpha}, \bar{\alpha})$, implies

$$
W(\underline{\alpha}, p(\underline{\alpha}))+\sigma R[\underline{\alpha}] \geq W(\underline{\alpha}, p(\bar{\alpha}))+\sigma R[\bar{\alpha}]
$$

Rearranging terms we have

$$
\sigma(R[\underline{\alpha}]-R[\bar{\alpha}]) \geq W(\underline{\alpha}, p(\bar{\alpha}))-W(\underline{\alpha}, p(\underline{\alpha}))
$$

Since in equilibrium $p(\bar{\alpha})=p^{*}(\bar{\alpha})$ and $\lambda\left(p^{*}(\bar{\alpha})-p(\underline{\alpha})\right)=W\left(\underline{\alpha}, p^{*}(\bar{\alpha})\right)-W(\underline{\alpha}, p(\underline{\alpha}))$, substituting we have

$$
\lambda\left(p^{*}(\bar{\alpha})-p(\underline{\alpha})\right) \leq \sigma[R[\underline{\alpha}]-R[\bar{\alpha}]]
$$

In any equilibrium of this game $p(\underline{\alpha}) \leq p^{*}(\underline{\alpha})$, and in this range $W(\underline{\alpha}, p(\underline{\alpha}))$ increases in $p(\underline{\alpha})$, up to $p^{*}(\bar{\alpha})$. It implies that $\lambda\left(p^{*}(\bar{\alpha})-p(\underline{\alpha})\right)$ is a monotonic decreasing function of prices $p(\underline{\alpha})$, and therefore it has an inverse, $\lambda^{-1}(.){ }^{3}$ Hence,

$$
p(\underline{\alpha}) \geq p^{*}(\bar{\alpha})-\lambda^{-1}[\sigma[R[\underline{\alpha}]-R[\bar{\alpha}]]]
$$

Using the same argument for the high type restriction, $\Phi(\bar{\alpha}, \bar{\alpha}) \geq \Phi(\bar{\alpha}, \underline{\alpha})$, the following condition can be derived:

$$
p(\underline{\alpha}) \leq p^{*}(\bar{\alpha})-\lambda^{-1}[\sigma[R[\underline{\alpha}]-R[\bar{\alpha}]]]
$$

Since in equilibrium both conditions must hold, it implies that

$$
p(\underline{\alpha})=p^{*}(\bar{\alpha})-\lambda^{-1}[\sigma[R[\underline{\alpha}]-R[\bar{\alpha}]] .
$$

The distortion of the pro-consumer type is given by $\lambda\left(p^{*}(\underline{\alpha})-p(\underline{\alpha})\right)>0$. In equilibrium the distortion of the lower type is a function of the difference between the probability of each type winning the election, and on how the incumbent weighs his objective function. The greater the chance of the lower type winning the election compared to the higher type, the more the lower

\footnotetext{
${ }^{3} \lambda($.) is increasing in prices for price levels exceeding the one that maximizes the social welfare. It is not relevant since in equilibrium no price will fall in that region.
} 
type will distort to run away from the higher type. Also, the more weight the politician puts on being re-elected compared to the consumer welfare, the more he will distort.

It is worth noticing that without loss of generality we consider only the case where signaling happens. No signaling happens when $p^{*}(\underline{\alpha})<p(\underline{\alpha})<p^{*}(\bar{\alpha})$, since the high type will not try to mimic the low type anyway, and both types will set prices that maximize the social welfare.

We proved here that, in equilibrium, some government-regulators (in our model, the proconsumer type) will distort and lower the regulated price to differentiate themselves from other types of regulators (pro-industry). Hence, one empirical implication of our discrete, twotype regulator model is that the political cycle in regulated industries only takes place when a pro-consumer regulator is in office, which happens with probability $(1-\mu)$. While our model is sufficient to give the main insights justifying a political cycle in regulated prices, a model allowing for a continuum of regulator types would be more realistic since it would allow for cycles of different intensities. In the continuum of types case, everyone but the most proindustry type would lower the price before elections to differentiate themselves from the type immediately below. Everything else constant, the probability distribution of the regulated price would then follow the distribution of regulator types. Earlier models accounted for the political nature of the regulatory process but could not rationalize a political cycle in the regulated price. The model developed here results in such cycles even when rational voters are able to understand the process and the strategy of the incumbent.

\section{EMPIRICAL EVIDENCE}

\section{A. The Market}

Our model of political price cycles in regulated industries is tested for the gasoline market in various countries. The choice of gasoline as a product whose price may be affected by the electoral cycle is justified mainly by the fact that gasoline is a fairly homogeneous product purchased regularly by a high number of people who are therefore likely to remember its price. Moreover, gasoline prices are a major determinant of transportation costs, thus directly and indirectly affecting inflation and consumer welfare. ${ }^{4}$

Extensive media coverage of gasoline price fluctuations simultaneously attests the importance of gasoline in people's daily routines and increases the visibility of such fluctuations, thereby raising the likelihood that an electorally concerned government-regulator may try to influence them. For instance, an article recently published on the front page of the Washington Post states that "rising fuel prices are stoking popular anger around the world, throwing politicians on the defensive and forcing governments to resort to price freezes, tax cuts and other

\footnotetext{
${ }^{4}$ In addition, Paiva (1995) provides evidence of the occurrence of a political cycle in gasoline prices in Brazil.
} 
measures to soothe voter resentment." This quote also illustrates another assumption we make in using the gasoline market in the empirical part of our paper: that governments either determine gasoline prices directly through price regulation or exert strong influence on them through regulatory stocks, importation, taxes, subsidies, and when setting environment and safety standards. ${ }^{6}$ Note that the model derived in the previous section can be easily adapted to incorporate indirect price regulation strategies.

\section{B. The Data}

The initial dataset comprised quarterly series on the evolution of domestic gasoline prices, consumer price indexes, and exchange rates of the domestic currency against the U.S. dollar for 32 industrial and developing countries during 1978-2004. A list of the countries covered can be found in the appendix. Countries were included in the sample based on data availability. Because some countries did not have gasoline price or exchange rate data for every quarter in the sample period, the maximum number of observations in the pool was 2,915 . The dataset also included a series with average international oil prices expressed in U.S. dollars as well as a dummy variable for each country in the sample indicating the quarters in which elections for parliament or congress occurred. ${ }^{7}$ Only legislative elections were considered here because every country in the sample had at least one election of this type during the period analyzed. In contrast, presidential elections either do not take place or are less relevant in the many countries where a parliamentary regime is in place.

Domestic gasoline prices were obtained from the Energy Prices and Taxes Database published by the Organization for Economic Cooperation and Development (OECD). Consumer prices and exchange rates were taken from International Finance Statistics, while international crude oil prices came from the Commodity Price System Database, both compiled by the IMF. Election dates were found in the Election Results Archive maintained by the Center on Democratic Performance at Binghamton University (State University of New York).

Seeking some preliminary evidence of the occurrence of a political cycle in the real price of gasoline, for each country in the sample we created a variable named gasprofit that measures how much the real price of gasoline changes in comparison to the real change in the cost of oil

\footnotetext{
5 "High Oil Prices Met With Anger Worldwide_-Both Rich and Poor Countries Make Moves to Appease Citizens," by Paul Blustein and Craig Timberg, Washington Post, October 3, 2005.

6 Illustrating this point, news agencies reported on April 25, 2006, that gasoline futures prices dropped 4 percent immediately following remarks by President George W. Bush that he was ordering a temporary suspension of environmental rules for gasoline and a temporary halt on the U.S. government's purchase of crude oil for its emergency reserves. Some analysts linked this decision to political concerns over rising gasoline prices.

${ }^{7}$ The international oil price used in this study was calculated as a simple average of three crude oil spot prices: Dated Brent, West Texas Intermediate, and the Dubai Fateh.
} 
expressed in domestic currency. The idea is that while real gasoline prices can be expected to vary broadly in line with international oil prices and the real exchange rate, a politically motivated government or regulator would resist passing these higher production costs onto the domestic gasoline price in the run-up to an important election. The variable gasprofit is thus defined as:

$$
\text { gasprofit }=[(1+\text { cpgas }) \div(1+\text { cpoildomcur })]-1\} * 100
$$

where cpgas is the percentage change in gasoline prices and cpoidomcur is the percentage change in the international oil price expressed in domestic currency.

Interestingly, pooling all countries together and considering the full sample period of 1978-2004, the variable gasprofit increased at an average of 1.4 percent during "normal" quarters and declined by 0.4 percent in periods with electoral activity. ${ }^{8}$ Indicating that this difference is not the result of a few outlier countries, the average change in gasprofit during electoral quarters was lower than the average change in "normal" quarters in 25 of the 32 countries in the sample. Moreover, in the majority of the countries surveyed, the increase in real gasoline prices fell short of the increase in oil costs expressed in real domestic currency units during periods of electoral campaign: the average change in gasprofit during electoral quarters was negative in 23 countries of our sample; in contrast, that same average was negative during quarters with no election activity in only seven countries.

Focusing on real gasoline prices alone, we observed that they declined 0.3 percent, on average, during "normal" quarters and about 0.7 percent during quarters of electoral campaign; in 15 countries, this difference exceeded 2 percentage points, whereas in seven countries it exceeded 6 percentage points.

\section{Econometric Modeling}

Moving toward formal econometric modeling, the following variables were generated for each country in the sample: lrgas was defined as the natural logarithm of domestic gasoline prices minus the natural logarithm of domestic CPI; ldompoil is the natural logarithm of real oil prices expressed in domestic currency; and lrer is the natural logarithm of the exchange rate minus the natural logarithm of the domestic CPI. The series lpoilusd defined as the natural logarithm of international oil prices in U.S. dollars is also used in some model specifications. Unit root tests (available from the authors) were not conclusive regarding the stationarity of the series in levels, as the different test statistics yielded conflicting results. ${ }^{9}$ Nonetheless, all tests indicated the first differences of the series to be stationary. Econometric estimations were therefore carried out with the variables in first differences.

\footnotetext{
${ }^{8}$ Electoral activity is considered to take place in the election quarter and in the quarter immediately preceding the election quarter.

${ }^{9}$ We carried out stationarity tests that assume a common unit root process and others that assume individual unit root processes; each category of test had three alternative statistics.
} 
Our basic model simply relates the evolution of real gasoline prices in each country to the real cost of oil expressed in domestic currency and the electoral calendar, thus having the following general specification:

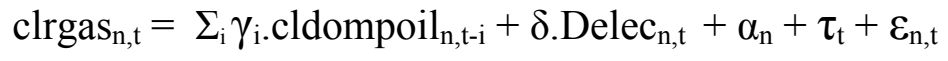

where

$\operatorname{clrgas}_{n, t}$ is the change in lrgas in country $n$ at time $t$

cldompoil $_{t-i}$ is the change in ldompoil at time $t-i$

Delec $_{n, t}$ is a dummy variable that assumes the value 1 if an election is to take place in country $n$ either in the current or in the next quarter and zero otherwise

$\alpha_{\mathrm{n}}$ are country specific effects (fixed or random)

$\tau_{\mathrm{t}}$ are period specific effects (fixed or random)

$\varepsilon_{\mathrm{n}, \mathrm{t}}$ are residuals

$0 \leq \mathrm{i} \leq 4$ is the number of lags of the explanatory variables entering different variations of the basic model

and $\gamma_{\mathrm{i}}$ and $\delta$ are parameters to be estimated

Six variants of the basic model are summarized in Table 1 and show that the electoral dummy coefficient estimates $(\delta)$ are always negative and highly significant, therefore pointing toward the existence of a political cycle in gasoline markets. The model selection process started with a specification that included only contemporaneous values of domestic oil costs and both country and period specific effects (first column). However, $F$-tests on the significance of these individual effects indicated the country specific effects to be redundant. A Hausman test subsequently rejected the specification with random period effects (second column). ${ }^{10}$ The model estimated with fixed period effects thus emerged as our preferred specification (third column). It indicates that suppliers and regulators generally chose to smooth out fluctuations in fuel costs, passing onto domestic gasoline prices, on average, only about 16 percent of the contemporaneous changes in the cost of oil expressed in domestic currency. More importantly, the estimated coefficient $\delta$ suggests that regulators tend to lower real gasoline prices by 0.9 percent during periods of election campaign, a relatively sharp decline compared to the quarterly average reduction of 0.3 percent for the entire sample period.

\footnotetext{
${ }^{10}$ Seasonal dummy variables were added to specifications with time random effects.
} 
Table 1. Real Gasoline Prices, Oil Costs, and Elections: Basic Model

\begin{tabular}{|c|c|c|c|c|c|c|}
\hline & 1 & 2 & 3 & 4 & 5 & 6 \\
\hline cldompoil $_{t}$ & $\begin{array}{c}0.156^{* *} \\
(3.38)\end{array}$ & $\begin{array}{c}0.194^{* *} \\
(12.15)\end{array}$ & $\begin{array}{c}0.156^{* *} \\
(7.64)\end{array}$ & $\begin{array}{c}0.206^{* *} \\
(3.66)\end{array}$ & $\begin{array}{c}0.225^{* *} \\
(5.67)\end{array}$ & $\begin{array}{c}0.206^{* *} \\
(3.71)\end{array}$ \\
\hline cldompoil $_{t-1}$ & & & & $\begin{array}{c}0.170^{* *} \\
(2.54)\end{array}$ & $\begin{array}{c}0.164^{* *} \\
(4.52)\end{array}$ & $\begin{array}{c}0.170^{* * *} \\
(2.57)\end{array}$ \\
\hline Delec & $\begin{array}{c}-0.009 * * \\
(-2.24)\end{array}$ & $\begin{array}{c}-0.009^{*} \\
(-1.93)\end{array}$ & $\begin{array}{c}-0.009 * * \\
(-2.03)\end{array}$ & $\begin{array}{c}-0.008^{* *} \\
(-2.09)\end{array}$ & $\begin{array}{c}-0.008 * * \\
(-2.03)\end{array}$ & $\begin{array}{c}-0.008^{* * *} \\
(-2.05)\end{array}$ \\
\hline Country effects & Fixed & None & None & Fixed & None & None \\
\hline Period effects & Fixed & Random & Fixed & Fixed & Random & Fixed \\
\hline Method & LS & GLS & LS & LS & LS & LS \\
\hline Adjusted $R$-squared & 0.30 & 0.05 & 0.31 & 0.32 & 0.10 & 0.32 \\
\hline No. of observations & 2,937 & 2,937 & 2,937 & 2,913 & 2,913 & 2,913 \\
\hline Hausman statistic p-value & & 0.006 & & & 0.351 & \\
\hline
\end{tabular}

** $(*)$ indicates significance at the 5 percent level (10 percent level).

Note: Numbers in parenthesis are $t$-ratios.

Model specifications that include lagged oil costs among the explanatory variables are summarized in the last three columns of Table 1. Up to 4 lags of the cost of oil were added to the model $(i \leq 4)$, but only the first lag reached minimum significance levels and improved the regression fit as measured by the adjusted $R$-squared. We started once again from a broad specification with both country and period fixed effects (column 4 ), but $F$-tests confirmed that the country fixed effects remain redundant in the new specification. Hausman test no longer rejects the specification with random period effects (column 5), although the model with period fixed effects still yields the highest adjusted $R$-squared (column 6 ). The electoral dummy variable remains highly significant in all specifications, suggesting that real gasoline prices are reduced by about 0.9 or 0.8 percent during quarters of electoral activity, on average, in all 32 countries. Since we do not expect the occurrence of political price cycles in all countries at all times, it is reasonable to assume that the decline in real gasoline prices would be significantly more pronounced in the countries where a cycle is in fact observed.

In order to further assess the robustness of our results, we re-estimated regressions similar to the ones above but allowing the coefficients on the current and lagged values of domestic oil 
costs to be different for each country in the sample. ${ }^{11}$ The results are summarized in Table 2 and generally portray electoral dummy coefficients that are even more significant than in the previous specifications. Moreover, the country-specific coefficients on current and lagged oil costs are strongly significant in almost every case, thus improving the fit of the regressions.

Table 2. Real Gasoline Prices, Oil Costs, and Elections: Modified Basic Model

\begin{tabular}{|c|c|c|c|c|c|c|}
\hline & 1 & 2 & 3 & 4 & 5 & 6 \\
\hline $\begin{array}{l}\text { cldompoil }_{\mathrm{t}} \\
\text { (country-specific) }^{\text {cous }}\end{array}$ & Yes & Yes & Yes & Yes & Yes & Yes \\
\hline $\begin{array}{l}\text { cldompoil }_{t-1} \\
\text { (country-specific) }\end{array}$ & No & No & No & Yes & Yes & Yes \\
\hline Delec & $\begin{array}{l}-0.010 * * \\
(-2.23)\end{array}$ & $\begin{array}{c}-0.009 * * \\
(-2.20)\end{array}$ & $\begin{array}{c}-0.009 * * \\
(-2.21)\end{array}$ & $\begin{array}{c}-0.010 * * \\
(-2.66)\end{array}$ & $\begin{array}{c}-0.009 * * \\
(-2.61)\end{array}$ & $\begin{array}{l}-0.010 * * \\
(-2.43)\end{array}$ \\
\hline Country effects & Fixed & None & None & Fixed & None & None \\
\hline Period effects & Fixed & Random & Fixed & Fixed & Fixed & Random \\
\hline Method & LS & GLS & LS & LS & LS & GLS \\
\hline Adjusted $R$-squared & 0.36 & 0.13 & 0.37 & 0.40 & 0.40 & 0.23 \\
\hline No. of observations & 2,937 & 2,937 & 2,937 & 2,913 & 2,913 & 2,913 \\
\hline Hausman statistic p-value & & 0.556 & & & & 0.112 \\
\hline
\end{tabular}

As another test for the robustness of the main results to different model specifications, we also estimate a model in which international oil prices in U.S. dollars and the real exchange rate enter the real gasoline price equation separately, as follows: ${ }^{12}$

$$
\operatorname{clrgas}_{n, t}=\Sigma_{i} \lambda_{i} \cdot \text { clpoilusd }_{t-i}+\Sigma_{i} \mu_{i} \cdot \text { clrer }_{n, t-i}+\delta . \text { Delec }_{n, t}+\alpha_{n}+\tau_{t}+\varepsilon_{n, t}
$$

where

\footnotetext{
${ }^{11}$ Instead of a single coefficient for each lag of the explanatory variable we would have $\gamma_{\mathrm{i}, \mathrm{n}}$ with $\mathrm{n}=1,2, \ldots, 32$.

${ }^{12}$ Introducing these costs factors as separate explanatory variables allows for the possibility that regulators react differently to cost increases (reductions) stemming from weaker (stronger) domestic currency or higher (lower) international oil prices.
} 
clpoilusd $_{t-i}$ is the change in lpoilusd at time $t-i$

clrer $_{n, t-i}$ is the change in lrer in country $n$ at time $t-i$

$0 \leq \mathrm{i} \leq 4$ is the number of lags of the explanatory variables entering different variations of the model

and $\lambda_{\mathrm{i}}, \mu_{\mathrm{i}}$, and $\delta$ are parameters to be estimated.

Variations of the model given in (2) were estimated with common and country-specific coefficients $\lambda_{\mathrm{i}}$ and $\mu_{\mathrm{i}}$ and the results are summarized in Table 3 .

Table 3. Real Gasoline Prices, Oil Costs, and Elections: Alternative Model

\begin{tabular}{|c|c|c|c|c|c|c|}
\hline & 1 & 2 & 3 & 4 & 5 & 6 \\
\hline clpoilusd $_{t}$ & common & common & common & common & $\begin{array}{l}\text { country } \\
\text { specific }\end{array}$ & $\begin{array}{l}\text { country } \\
\text { specific }\end{array}$ \\
\hline clpoilusd $_{t-1}$ & common & common & common & common & $\begin{array}{l}\text { country } \\
\text { specific }\end{array}$ & $\begin{array}{l}\text { country } \\
\text { specific }\end{array}$ \\
\hline clrer $_{t}$ & common & common & common & $\begin{array}{l}\text { country } \\
\text { specific }\end{array}$ & common & $\begin{array}{l}\text { country } \\
\text { specific }\end{array}$ \\
\hline clrer $_{t-1}$ & common & common & common & $\begin{array}{l}\text { country } \\
\text { specific }\end{array}$ & common & $\begin{array}{l}\text { country } \\
\text { specific }\end{array}$ \\
\hline Delec & $\begin{array}{c}-0.008 * * \\
(-2.15)\end{array}$ & $\begin{array}{c}-0.008 * * \\
(-2.11)\end{array}$ & $\begin{array}{c}-0.009 * * \\
(-2.18)\end{array}$ & $\begin{array}{c}-0.007 * * \\
(-1.97)\end{array}$ & $\begin{array}{c}-0.010 * * \\
(-2.52)\end{array}$ & $\begin{array}{c}-0.010 * * \\
(-2.32)\end{array}$ \\
\hline Country effects & Fixed & None & Fixed & Fixed & None & Fixed \\
\hline Period effects & Random & Random & None & None & Random & None \\
\hline Method & GLS & GLS & LS & LS & GLS & LS \\
\hline Adjusted $R$-squared & 0.10 & 0.11 & 0.25 & 0.16 & 0.20 & 0.35 \\
\hline No. of observations & 2,913 & 2,913 & 2,913 & 2,913 & 2,913 & 2,913 \\
\hline
\end{tabular}

** $(*)$ indicates significance at the 5 percent level (10 percent level).

Once again, only the first lag of explanatory variables reached minimum significance levels. Because international oil prices in U.S. dollars are the same for every country in the sample, equation (2) cannot be estimated with period fixed effects, as these would introduce perfect colinearity among regressors. Notice that the electoral dummy variable remains highly significant in the various specifications, in the presence of fixed and/or random individual effects, and whether common or country-specific coefficients are estimated for the 
explanatory variables. The point estimates suggest that the real price of gasoline declines by at least 0.7 percent and up to 1 percent, on average, during quarters of election campaign in the 32 countries covered by our sample.

\section{CONCluding Remarks}

This paper presented a model of industry regulation where information asymmetries and the government-regulator's interest in being re-elected may generate a political cycle in the regulated price. Quarterly data covering 32 countries during 1978-2004 provided strong evidence of the occurrence of a political cycle in gasoline prices.

Our model characterizes the behavior of the government-regulator as an attempt to maximize an objective function comprised of the social welfare in the regulated market and the government's chance of being reelected. The social welfare function follows a stochastic process in which the weights attributed to consumers' utility and firms' profits are determined by a shock at the beginning of an election period. This shock may reflect changing political alliances or economic conditions exogenous to the regulated market. Because this shock is not immediately observable to consumer-voters, the incumbent government-regulator may have incentives to set a price below the welfare-maximizing price to signal its pro-consumer nature and thus attract more votes in the upcoming election. In fact, our model derives equilibrium regulation strategies in which some types of government-regulator will lower the regulated price in an election period, thus generating a political price cycle in the regulated industry.

We tested the implications of our model for the gasoline market in the 32 industrial and developing countries for which data were available. The choice of the gasoline market is justified by the impact it has on consumers' utility, the visibility that fluctuations in gasoline prices have, and the various ways - besides direct price determination - through which governments can influence domestic gasoline prices. Simple statistical analysis revealed that changes in gasoline prices were, on average, 1.4 percent above changes in domestic oil costs during "normal" quarters and 0.4 percent below during periods immediately preceding an election. Focusing on real gasoline prices alone, we observed that they declined 0.3 percent, on average, during "normal" quarters and about 0.7 percent during quarters of electoral campaign. Moreover, in 15 countries of the sample, this difference exceeded 2 percentage points, whereas it exceeded 6 percentage points in seven countries.

Econometric modeling also point toward the existence of a political cycle in gasoline prices. Simple equations linking gasoline prices to changes in the cost of oil to domestic gasoline producers (which is assumed to be driven by international oil prices and the exchange rate) and dummy variables indicating periods of electoral activity were estimated using panel data techniques. Our estimates consistently yielded negative and significant coefficients on the electoral dummy variable, suggesting that after controlling for cost changes, gasoline prices are reduced during periods of electoral activity. In fact, point estimates suggest that the real price of gasoline declines by at least 0.8 percent and up to 1 percent, on average, during each of the two quarters of election campaign in the 32 countries covered by our sample, a relatively sharp decline compared to the average reduction of 0.3 percent in the entire sample 
period. These results were robust across various model specifications. Since we do not expect the occurrence of political price cycles in all countries at all times, it is reasonable to assume that the decline in real gasoline prices would be significantly more pronounced in the countries where a cycle is in fact observed. 


\section{Appendix 1. List of Countries Included in the Empirical Work}

The 32 countries in our sample are the following:

$\begin{array}{llll}\text { Australia } & \text { France } & \text { Korea } & \text { Slovak Republic } \\ \text { Austria } & \text { Germany } & \text { Mexico } & \text { South Africa } \\ \text { Belgium } & \text { Greece } & \text { Netherlands } & \text { Spain } \\ \text { Brazil } & \text { India } & \text { New Zealand } & \text { Sweden } \\ \text { Canada } & \text { Indonesia } & \text { Norway } & \text { Thailand } \\ \text { Switzerland } & \text { Ireland } & \text { Poland } & \text { Turkey } \\ \text { Denmark } & \text { Italy } & \text { Portugal } & \text { United Kingdom } \\ \text { Finland } & \text { Japan } & \text { Romania } & \text { United States }\end{array}$




\section{REFERENCES}

Alesina, A., 1987, "Macroeconomic Policy in a Two-Party System as a Repeated Game," Quarterly Journal of Economics, Vol. 102, No. 3 (August), pp. 651-78.

Becker, G., 1983, “A Theory of Competition Among Pressure Groups for Political Influence,” Quarterly Journal of Economics, Vol. 98, No. 3 (August), pp. 371-400.

Hibbs, D., 1977, "Political Parties and Macroeconomic Policy," The American Political Science Review, Vol. 7 (December), pp. 1467-87.

Laffont, J.J. and J. Tirole, 1993, A Theory of Incentives in Procurement and Regulation, (Boston: The MIT Press).

Nordhaus, W., 1975, “The Political Business Cycle,” Review of Economic Studies, Vol. 42 (April), pp. 169-90.

Paiva, C,. 1996, "Electoral Price Cycles in Regulated Industries," World Development, Vol. 24, No. 10, pp. 1673-80.

Peltzman, S., 1976, “Toward a More General Theory of Regulation,” Journal of Law and Economics, Vol. 19 (August), pp. 211-40. , 1993, "George Stigler's Contribution to the Economic Analysis of Regulation," The Journal of Political Economy, Vol. 101, No. 5 (October), pp. 818-32.

Rogoff, K., 1990, “Equilibrium Political Budget Cycles,” American Economic Review, Vol. 80, No. 1 (March), pp. 21-36. , and A. Sibert, 1988, "Elections and Macroeconomic Policy Cycle," The Review of Economic Studies, Vol. 55, No. 1 (January), pp. 1-16.

Spence, M., 1973, “Job Market Signaling," The Quarterly Journal of Economics, Vol. 87, No. 3 (August), pp. 355-74.

Spiller, P., 1990, "Politicians, Interest Groups, and Regulators: A Multiple-Principals Agency Theory of Regulation, or Let Them be Bribed," Journal of Law and Economics, Vol. 33 (April), pp. 65-102.

Stigler, G.J., 1971, “The Theory of Economic Regulation,” Bell Journal of Economics And Management Science, Vol. 2 (Spring), pp. 3-21.

Tufte, E.R., 1978, The Political Control of the Economy, (Princeton, New Jersey: Princeton University Press). 